\title{
ARTIGO CIENTIFICO \\ Potencial de extratos etanólicos de propólis e extratos aquosos de plantas espontâneas no controle de doenças pós-colheita do morango
}

\section{Potential of propolis extracts and extracts etanol spontaneous plants aqueous in control of diseases of strawberry post-harvest}

\author{
Gabriela Silva Moura ${ }^{1}$; Jonas Marcelo Jaski ${ }^{2}$; Gilmar Franzener ${ }^{3 *}$
}

\begin{abstract}
Resumo: A cultura do morangueiro é severamente acometida por várias doenças, dentre elas o mofo cinzento, causado por Botrytis cinerea é considerada a doença mais severa na pós-colheita. Visando reduzir o uso de fungicidas sintéticos, vem sendo realizadas pesquisas propondo a utilização de métodos alternativos de controle de patógenos pós-colheita envolvendo a utilização de extratos vegetais, uso de biofungicidas e óleos essenciais. Assim, o presente trabalho teve como objetivo avaliar o potencial de diferentes extratos de própolis e plantas espontâneas no controle de podridão pós-colheita causada pelo fungo $B$. cinerea em morangos. Para avaliar a atividade antifúngica direta dos extratos etanólico de própolis e extratos aquosos de plantas espontâneas sobre B. cinerea, foi realizado o experimento in vitro, utilizando-se os tratamentos própolis verde $0,5 \%$; própolis verde 2,5\%; própolis marrom $0,5 \%$; própolis marrom 2,5\%; língua-de-vaca 10\%; assa-peixe 10\%; rubim 10\%; tansagem 10\%; testemunha (água). As medições do diâmetro das colônias foram iniciadas 48, 72 e 96 horas após a instalação do experimento. No experimento in vivo os frutos foram imersos nos tratamentos descritos acima. Após cinco dias avaliou-se a incidência e severidade da doença mofo cinzento e das doenças pós-colheita como antracnose e podridão de Rhizopus que apareceram no experimento. Utilizou-se o delineamento experimental inteiramente casualizado (DIC) com quatro e cinco repetições para o ensaio in vitro e in vivo, respectivamente. Os resultados mostram que os extratos etanólicos de própolis verde e marrom a 2,5\% apresentaram in vitro e in vivo atividade antifúngica a $B$. cinerea e Rhizopus nigricans, respectivamente.
\end{abstract}

Palavras-chave: Atividade antifúngica. Botrytis cinerea. Métodos alternativos. Plantas medicinais.

\begin{abstract}
The strawberry crop is severely affected by various diseases, including gray mold, caused by Botrytis cinerea is considered the most severe disease in post-harvest fruit. To reduce the use of synthetic fungicides, has been carried out research proposing the use of alternative methods of control postharvest pathogens involving the use of plant extracts, use of biofungicides, essential oils among others. Thus, this study aimed to evaluate the potential of different propolis extracts and wild plants in the control of post-harvest rot caused by the fungus Botrytis cinerea in strawberries. To evaluate the direct antifungal activity of ethanolic extracts of propolis and aqueous extracts of wild plants of B. cinerea, the in vitro experiment was performed, using treatments propolis $0.5 \%$; propolis $2.5 \%$; brown propolis $0.5 \%$; brown propolis $2.5 \%$; control (water + alcohol $2 \%$ ); cow tongue $10 \%$; assa-fish $10 \%$; rubim 10\%; tansagem 10\%; control (water). Measurements of the diameter of the colonies were started 48, 72 and 96 hours after installation of the experiment. Conducted the in vivo experiment in which the fruits of strawberry plants were immersed in the treatments described above. After five days we evaluated the incidence and severity of gray mold disease and post-harvest diseases such as anthracnose and Rhizopus rot appearing in the experiment. We used a completely randomized design (CRD) with four and five replicates for the in vitro assay and in vivo, respectively. The results show that ethanol extracts of green and brown propolis $2.5 \%$ presented in vitro and in vivo antifungal activity to $B$. cinerea and Rhizopus nigricans respectively.
\end{abstract}

Key words: Antifungal activity. Botrytis cinerea. Alternative methods. Medicinal plants

\footnotetext{
*Autor para correspondência

Recebido para publicação em 03/04/2016; aprovado em 25/12/2016

${ }^{1}$ Pós-doutoranda em Agroecologia e Desenvolvimento Rural Sustentável (PNPD-CAPES), Universidade Federal da Fronteira Sul (UFFS), Campus Laranjeiras do Sul - PR; E-mail: bismoura@hotmail.com.

${ }^{2}$ Mestrando em Agronomia, Universidade Estadual de Maringá (UEM), E-mail: jonasmjaski@ hotmail.com.

${ }^{3}$ Doutor em Agronomia (UEM). Professor da Universidade Federal da Fronteira Sul (UFFS), Campus Laranjeiras do Sul - PR; E-mail: gilmar.franzener@uffs.edu.br.
} 


\section{INTRODUÇÃO}

Atualmente, as chamadas "pequenas frutas", vem apresentando um grande aumento na produção, com destaque para a cultura do morangueiro (Fragaria x ananasa Duch. Ex. Rozier) cujos frutos (pseudofrutos), tem sido muito apreciados pelos consumidores, devido suas características sensoriais, alto teor nutricional, sendo rico em vitamina $\mathrm{C}$ e ácido fólico, compostos bioativos como polifenóis e betacaroteno, minerais e outras vitaminas como A, B1 e B2. Além desses benefícios vitamínicos, os frutos do morangueiro contêm substâncias como flavonoides e antocianinas que atuam como antioxidantes, prevenindo doenças cardiovasculares, cânceres entre outras doenças (SIMARELLI, 2006; VENENCIO, 2010).

Segundo a FAO (2014), no cenário mundial a produção de morango é cerca de 4,52 milhões de toneladas, sendo os Estados Unidos, o maior produtor, com 1.366.850 toneladas. No Brasil, estima-se que a produção é de aproximadamente 133 mil toneladas, destacando como maiores produtores de morango os Estados de Minas Gerais, São Paulo e Rio Grande do Sul (EMATER, 2014).

Durante a colheita os frutos do morangueiro devem ser manipulados com muito cuidado, pois são frutos altamente perecíveis na pós-colheita, principalmente, devido a sua intensa atividade metabólica e grande suscetibilidade ao ataque de agentes patogênicos causadores de podridões (MALGARIM et al., 2006)

Foram relatadas mais de dez doenças pós-colheita em frutos de morango. Entre essas doenças, as mais importantes são o mofo cinzento, causada por $B$. cinerea Pers. Ex Fries, e a podridão de Rhizopus (Rhizopus nigricans) (TANAKA et al., 2005; ZAMBOLIM; COSTA, 2005), que comprometem a qualidade e a produção de morango (CANTILLANO; SILVA, 2010; REIS; COSTA, 2011).

O patógeno $B$. cinerea afeta todos os estágios de desenvolvimento do morangueiro, causando grandes prejuízos na produção. Quando não há nenhum tipo de controle as perdas na colheita do morangueiro podem chegar entorno de 30 a 40\%, já no caso de infestações agudas, as perdas podem chegar de 50 a $60 \%$ até ocasionar perdas econômicas de $100 \%$ (CSC, 2013). Outros fatores, como injúrias ocasionadas durante o procedimento de colheita e/ou formas de acondicionamento, danos nos frutos durante o transporte e comercialização favorecem o desenvolvimento do patógeno.

Em relação à forma de controle do patógeno, atualmente, as técnicas empregadas, durante as fases de pré e pós-colheita constituem-se principalmente na aplicação de fungicidas, os quais reduzem a qualidade do produto, oferecem riscos à saúde, restringem o mercado consumidor $\mathrm{e}$ causam prejuízos ambientais (DOTTO et al., 2011).

Neste contexto, o uso abusivo e indiscriminado de agrotóxicos na cultura do morangueiro tem despertado cada vez mais a preocupação entre os consumidores quanto à segurança alimentar (JARDIM; CALDAS, 2012) e o uso de alimentos livres de resíduos de agrotóxicos (MARQUENIE; LAMMERTYN; GEERAERD, 2002; VENZON et al., 2006).

Estudos visando à utilização de métodos alternativos no controle de doenças pós-colheita como o uso de extratos vegetais, biofungicidas e óleos essenciais são necessários (FRANCO; BETTIOL, 2000; BENATO et al., 2002; MOREIRA et al., 2002) e não devem buscar a mera substituição de agrotóxicos, mas demonstrar a importância de disponibilizar alternativas de manejo que favoreçam a sustentabilidade.

Para Schwarz et al. (2008), pesquisas com foco na utilização de métodos alternativos são importantes para o controle de perdas de qualidade em frutos, por possibilitar aumento do período de prateleira sem perdas por problemas fitossanitários e a redução no uso de agroquímicos. Já para Carvalho et al. (2009), a importância em se buscar tratamentos alternativos se deve aos aspectos de segurança dos mesmos, em função dos possíveis efeitos carcinogênicos e teratogênicos, bem como toxicidade residual. Segundo Sá et al. (2009) a utilização de alternativas que não agridam o meio ambiente é uma necessidade para a manutenção da sobrevivência humana.

Nos últimos anos, muitos trabalhos têm relatado o potencial de óleos essenciais e extratos de plantas medicinais como alternativa no controle de doenças pós-colheita (ALMEIDA et al., 2009; BRAGA, 2012; DEMARTELAERE et al., 2015; GEBEL; MAGURNO, 2014; MOURA et al., 2012; SAUTTER et al., 2011), entretanto, estudos direcionadas para a avaliar o potencial de plantas espontâneas no controle de doenças pós-colheita em frutos de morangueiro são escassos. Embora as plantas espontâneas, sejam tidas como daninhas ou invasoras, Lorenzi e Matos (2002) relatam que, muitas dessas plantas podem apresentar propriedades medicinais, representando alternativa na fitoterapia vegetal ou animal (BURG; MAYER, 2006).

Em face disto, este trabalho teve por objetivo avaliar o potencial de diferentes extratos de própolis e plantas espontâneas no controle de podridão pós-colheita causada pelo fungo Botrytis cinerea em morangos.

\section{MATERIAL E MÉTODOS}

O experimento foi conduzido no Laboratório de Fitopatologia da Universidade Federal da Fronteira Sul UFFS, Campus Laranjeiras do Sul, PR.

As plantas espontâneas, língua de vaca (Rumex crispus L.); assa-peixe (Vernonia polyanthes Less.); rubim (Leonurus sibiricus L.) e tansagem (Plantago tomentosa Lam.) foram coletadas no Campus da Universidade Federal da Fronteira Sul, Laranjeiras do Sul, PR, cujas coordenadas geográficas são: $25^{\circ} 26^{\prime} 42^{\prime}$ 'S e $52^{\circ} 26^{\prime} 29^{\prime}$ ' $\mathrm{W}, 850 \mathrm{~m}$ de altitude, no período de novembro de 2015. Para obtenção de extrato aquoso, as folhas frescas foram trituradas em liquidificador por $1 \mathrm{mim}$ na proporção de $10 \mathrm{~g}$ de folhas frescas em $100 \mathrm{~mL}$ de água destilada para obter extrato a $10 \%$. Em seguida o extrato foi filtrado e imediatamente utilizado na implantação do experimento. Para os ensaios foram também avaliadas própolis produzidas por abelhas Apis mellifera. A própolis verde foi obtida comercialmente da região de Ribeirão Preto, SP e a própolis marrom foi adquirida de um agricultor familiar no município de Laranjeiras do Sul, PR.

Para o experimento do crescimento micelial (in vitro) foi avaliada a atividade antifúngica direta dos extratos aquosos de plantas espontâneas e extrato etanólico de própolis (com 30\% de própolis in natura em etanol) sobre Botrytis cinerea. Constituíram tratamentos: própolis verde $0,5 \%$; própolis verde $2,5 \%$; própolis marrom $0,5 \%$; própolis marrom $2,5 \%$; testemunha (água + álcool 2\%); língua de vaca $10 \%$; assa-peixe $10 \%$; rubim $10 \%$; tansagem $10 \%$; testemunha (água). Os tratamentos foram incorporados em meio BDA e autoclavados por $20 \mathrm{~min}$ a $120^{\circ} \mathrm{C}$ a $1 \mathrm{~atm}$. Em seguida os 
meios foram vertidos em placas de Petri de nove centímetros de diâmetro. Duas horas após, um disco de nove $\mathrm{mm}$ de diâmetro, contendo micélio de $B$. cinerea com sete dias de idade, foi repicado para o centro de cada placa. Essas foram mantidas a $25^{\circ} \mathrm{C}$ em escuro por quatro dias. As avaliações foram realizadas através das medições diárias do diâmetro das colônias após 48, 72 e 96 horas a instalação do experimento, quando as maiores colônias cobriram $2 / 3$ da superfície do meio de cultura. Utilizou-se o delineamento experimental inteiramente casualizado (DIC) com quatro repetições.

Para avaliação in vivo, morangos sadios "Camarosa" foram obtidos em supermercado de Laranjeiras do Sul, PR e transportados imediatamente ao laboratório. Os tratamentos utilizados foram: própolis verde $0,5 \%$; própolis verde $2,5 \%$; própolis marrom $0,5 \%$; própolis marrom $2,5 \%$; testemunha (água + álcool 2\%); língua de vaca 10\%; assa-peixe $10 \%$; rubim 10\%; tansagem 10\%; testemunha (água).

Inicialmente os frutos de morango foram desinfestados em hipoclorito de sódio a $2 \%$ por 1 mim e lavados por duas vezes em água destilada estéril por 30 segundos. Após, os frutos foram deixados à temperatura ambiente para secar. Depois de secos, foram realizados dois ferimentos equidistantes nos frutos, os quais em seguida foram imersos por $1 \mathrm{~min}$ nos tratamentos citados anteriormente. Posteriormente os frutos foram aspergidos com suspensão aquosa calibrada para $1 \times 10^{5}$ esporos de $B$. cinerea por $\mathrm{mL}$, até o ponto de escorrimento.

Nas primeiras $24 \mathrm{~h}$ os frutos de morango foram acondicionados em câmara úmida, visando favorecer a ocorrência das doenças pós-colheita e permaneceram sobre a bancada do laboratório em temperatura de $18 \pm 2{ }^{\circ} \mathrm{C}$ e umidade relativa de $80 \pm 5 \%$. A incidência e severidade da doença mofo cinzento e de doenças pós-colheita como antracnose (Colletotrichum acutatum Simmons.) e podridão de Rhizopus (Rhizopus nigricansi Ehr.) que apareceram durante o experimento foram avaliadas após cinco dias. Para a avaliação da severidade das doenças foi considerado a seguinte escala: $0=$ frutos sem infecção; $1=25 \%$ do fruto infectado; $3=50 \%$ do fruto infectado; $4=100 \%$ do fruto infectado.

A identificação das doenças foi realizada com base nos sintomas visuais e a observação dos sinais dos patógenos, em microscópio de luz. Diagnosticada a etiologia do agente causal da podridão, o fruto foi descartado. O ensaio foi conduzido em delineamento experimental inteiramente casualizado (DIC) com cinco repetições de seis frutos por parcela. Os resultados obtidos nos experimentos foram submetidos a análise de variância e teste de Scott-Knott a 5\% de probabilidade com auxílio do programa estatístico Sisvar (FERREIRA, 2007).

\section{RESULTADOS E DISCUSSÃO}

Os resultados mostraram que houve diferença significativa nas três avaliações (in vitro) do crescimento micelial de Botrytis cinerea para os tratamentos com própolis verde 0,5 e $2,5 \%$ e própolis marrom $2,5 \%$ em relação à testemunha (Figura 1). Após 48 horas do início da implantação do experimento, foi observado maior inibição do crescimento micelial de $B$. cinerea no tratamento com própolis marrom $(2,5 \%)$ de $33,67 \%$, seguido do própolis verde $(2,5 \%)$ de $33,14 \%$ em relação a testemunha. Após 72 horas, observou-se inibição de 43,90\% para própolis verde $(2,5 \%)$ e $39,66 \%$ para própolis marrom $(2,5 \%)$. Na avaliação após 96 horas, observou-se inibição do crescimento micelial de $43,23 \%$ para própolis verde $(2,5 \%)$ e para própolis marrom de $38,53 \%$. Para o tratamento com própolis marrom $0,5 \%$ não houve diferença significativa em relação à testemunha. Esses resultados indicam o potencial inibidor tanto da própolis verde como da própolis marrom sobre o agente causal do mofo cinzento do morango.

Figura 1. Crescimento micelial de Botrytis cinerea, na presença de extratos etanólicos de própolis verde e marrom, avaliados após 48, 72 e 96 horas. *Medias seguidas pela mesma letra em cada avaliação, não diferem entre si pelo teste de Scott-Knott ao nível de $5 \%$ de probabilidade.

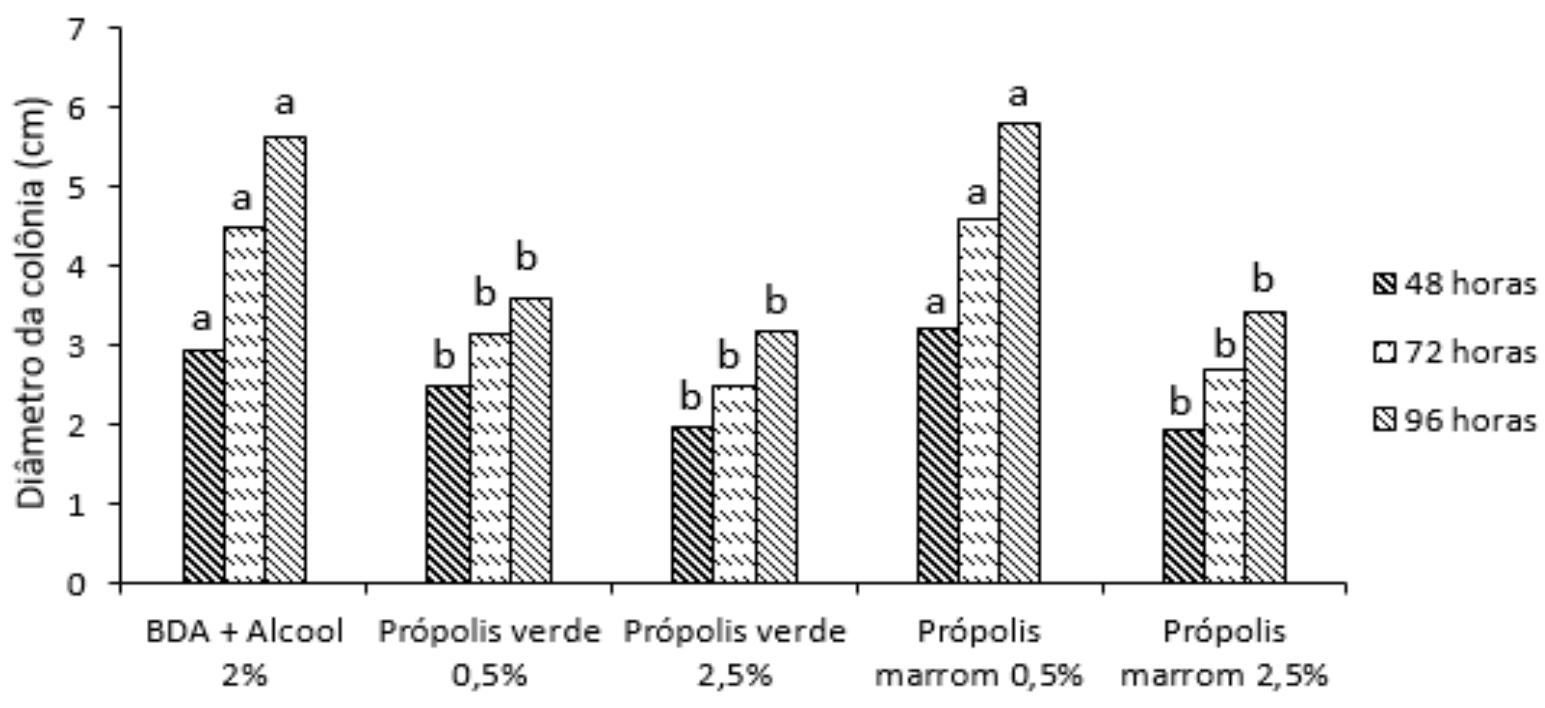

Ozcan (1999) mostrou em sua pesquisa efeito inibitório de extratos aquosos de própolis nas concentrações de 0,$5 ; 1 ; 2 ; 3$ e $4 \%$ sobre diferentes patógenos, com destaque para o B. cinerea. Em todos os fungos testados, foi observado inibição do crescimento micelial maior do que $50 \%$.

Outros trabalhos retratam o efeito antifúngico da própolis sobre o crescimento de fitopatôgenicos (BARBOSA 
et al., 2015; ALBANO et al., 2007; MORAES et al., 2011), porém, há casos em que esse efeito não é tão expressivo. Como é o caso do estudo realizado por Marini et al. (2012) que, observaram baixa atividade antifúngica in vitro do extrato etanólico de propólis nas concentrações de 0,$05 ; 0,1$; 0,$2 ; 0,4 ; 0,5$ e $1,0 \%$ sobre os fungos Phakopsora euvitis, Pseudocercospora vitis e Elsinoe ampelina.

$\mathrm{Na}$ literatura são poucos os estudos utilizando própolis em vegetais, principalmente para controle de doenças fúngicas. Piermann et al. (2007) testaram extrato de própolis obtido de produto comercial na concentração de $10 \%$ em oito diferentes fitobactérias: Pseudomonas syringae pv. tomato, $P$. corrugata, Clavibacter michiganensis subsp. michiganensis, Erwinia carotovora subsp. carotovora, Xanthomonas campestris pv. vesicatoria, $X$. translucens pv. undulosa, $X$. axonopodis pv. phaseoli e X. campestris pv. campestris. Esses autores conseguiram inibir de forma acentuada a multiplicação das bactérias em estudo, ao contrário do que ocorreu neste trabalho com o fungo $B$. cinerea em que não obtivemos resultados expressivos de inibição, sendo os tratamentos com própolis verde e marrom a 2,5\% que apresentaram maior inibição do crescimento micelial de $43,23 \%$ e 38,53\% respectivamente, em relação à testemunha.
Bianchini; Bedendo (1998) mostraram o efeito antimicrobiano in vitro do extrato de própolis a $10 \%$ no controle das bactérias fitopatogênicas Agrobacterium tumefaciens, Clavibacter michiganesis subsp. michiganensis e Xanthomonas axonopodis pv. phaseoli.

Para os tratamentos de língua de vaca, assa peixe e tansagem nas avaliações realizadas as 48 e 72 horas houve diferença significativa em relação à testemunha, observandose aumento do crescimento micelial do fungo quando submetido aos extratos das plantas espontâneas (Figura 2). Nestes mesmos tempos, não foi observado diferença significativa no crescimento micelial de $B$. cinerea em relação à testemunha para o extrato de rubim (10\%).

No período de avaliação após 96 horas observamos que houve diferença significativa para o crescimento micelial de Botrytis cinerea, para o tratamento com rubim (10\%), com inibição de 26,64\% em relação à testemunha (BDA). No tratamento com tansagem (10\%) não houve diferença significativa em relação à testemunha. Neste mesmo tempo de avaliação para os tratamentos assa-peixe e língua-de-vaca $(10 \%)$ observamos aumento do crescimento micelial do fungo em relação à testemunha (Figura 2).

Figura 2. Crescimento micelial de Botrytis cinerea, na presença de extratos aquosos de diferentes plantas espontâneas, avaliados após 48, 72 e 96 horas. *Medias seguidas pela mesma letra em cada avaliação, não diferem entre si pelo teste de Scott-Knott ao nível de $5 \%$ de probabilidade.

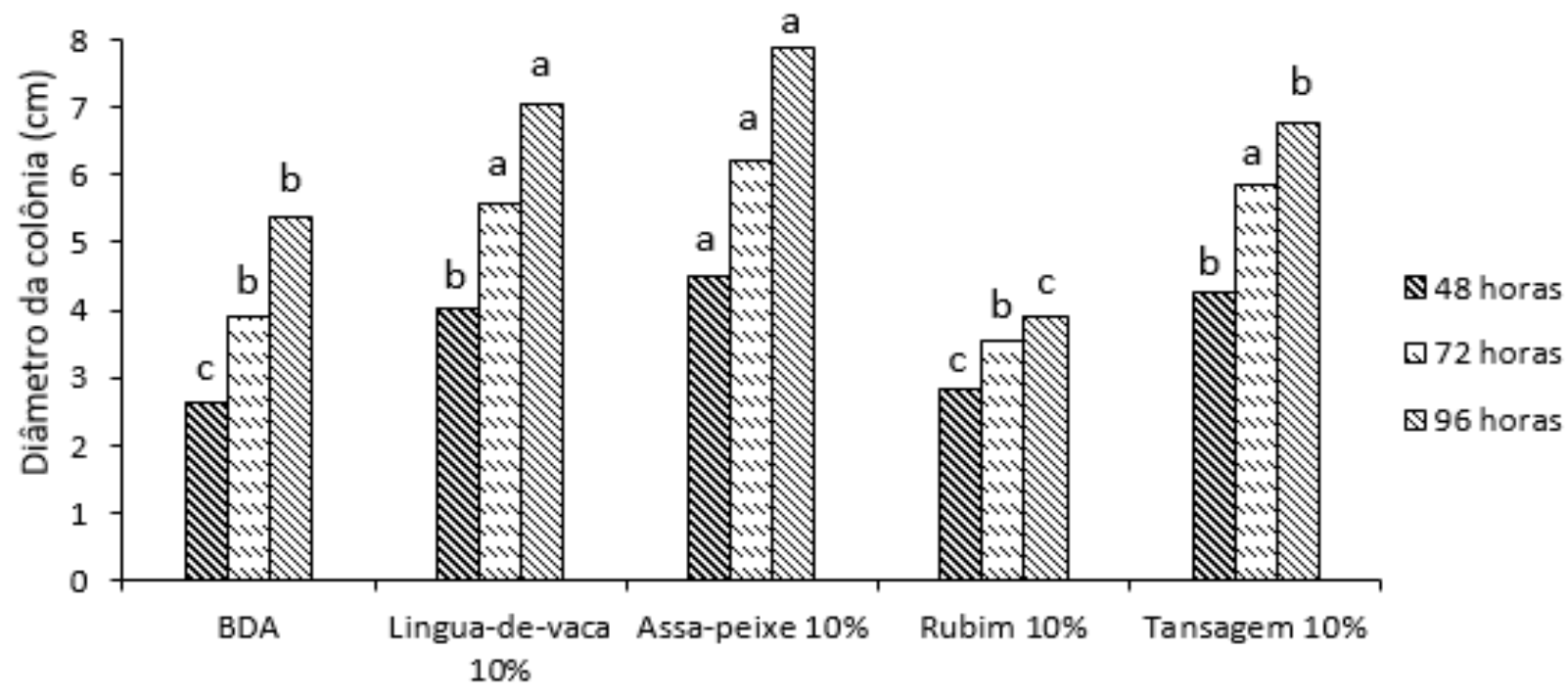

Diferentemente dos resultados obtidos nesta pesquisa, Rozwalka (2008) observou que os extratos aquosos de tansagem (10\%) estimularam o crescimento micelial do patógeno Colletotrichum gloeosporioides, diferindo estatisticamente da testemunha.

Pansera et al. (2015) relatam que em maiores concentrações o extrato etanólico de língua de vaca (20\%) inibiu totalmente o desenvolvimento do patógeno Sclerotinia sclerotiorum, entretanto os extratos quando preparados pelo método de infusão e aquoso não apresentaram diferenças significativas em relação ao controle e nem entre os tratamentos.

No experimento in vivo observou-se que a própolis verde $(0,5 \%)$ diminuiu a severidade da antracnose em frutos de morango, já os tratamentos com própolis marrom $(0,5 \%)$, própolis verde e marrom a 2,5\% não reduziram a incidência e

severidade das doenças avaliadas (Tabela 1). Estudos realizados por Medeiros et al. (2008) comprovaram que na menor concentração do extrato de própolis $(0,3 \%)$, houve redução da severidade da requeima da batata, causado por Phytophthora infestans. Por outro lado, os mesmos autores, observaram que na maior concentração do extrato de própolis (3\%) a redução da severidade da doença foi menor em relação à concentração de $0,3 \%$ do extrato.

De acordo com Silva (2009) é importante ressaltar que o potencial da própolis é atribuído pela sua complexa composição química, que tem como um fator a sazonalidade, pois seus compostos dependem do local de origem, da espécie vegetal na qual a abelha coletou a resina, da época do ano em que é colhida e da espécie da abelha.

A podridão de Rhizopus ocorreu com maior intensidade e severidade em morangos tratados com a 
própolis verde e marrom a $0,5 \%$ em relação à testemunha (Álcool 2\%), acredita-se que isto ocorreu devido à testemunha conter $2 \%$ de álcool, evitando a incidência do patógeno, já que os dois tipos de própolis em concentrações maiores $(2,5 \%)$ não diferiram da testemunha. Neste caso, conclui-se que o solvente foi à única variável que provavelmente interferiu diretamente na incidência do patógeno.

Pesquisa realizada por Silva (2009) para avaliar a atividade antifúngica de extratos aquosos e etanólicos de própolis sob diferentes patógenos verificaram que, os extratos etanólicos de própolis apresentaram maior capacidade de inibição fúngica quando comparados aos extratos aquosos.

Para a incidência e a severidade do mofo cinzento, os tratamentos com extratos etanólicos de própolis verde e marrom não apresentaram diferença significativa em relação à testemunha. Provavelmente, isto ocorreu devido às baixas concentrações de extratos etanólicos de própolis utilizadas no presente trabalho, não tendo um efeito significativo na incidência e severidade da doença. Vale salientar que outros estudos com diferentes concentrações de extratos de própolis devem ser realizados para obtenção de resultados mais promissores quanto ao seu efeito sobre patógenos póscolheita.
Pereira et al. (2014) avaliando o efeito do extrato etanólico de própolis à $4 \%$ sobre a severidade da antracnose do feijoeiro verificaram, reduções de até $63 \%$ na severidade da doença.

Lorenzetti (2012) mostrou que frutos de morangueiro submetido aos tratamentos por volatização do óleo essencial de canela, capim-limão, menta e eucalipto não apresentaram diferenças significativas em relação à incidência de mofo cinzento e outras podridões. O mesmo autor ainda diz que, pelo processo de imersão dos frutos nestes tratamentos descritos acima também não houve diferenças significativas, exceto para o tratamento com óleo essencial de eucalipto que apresentou menor incidência do mofo cinzento.

Estudos realizados por Tournas e Katsoudas (2005), verificaram também, além do gênero Botrytis em frutos de morangos, a presença de outros patógenos como Rhizopus, Penicillium, Fusarium, Alternaria, Cladosporium e Trichoderma. Os mesmo autores, atribuem o alto nível de contaminação deste fruto, quando comparado a outros, é devido ao conteúdo de açúcares e outros nutrientes, atividade de água ideal para o crescimento fúngico e baixo $\mathrm{pH}$ (TOURNAS; KATSOUDAS, 2005; VU et al., 2011).

Tabela 1. Incidência e severidade de doenças pós-colheita em morangos tratados com extratos etanólicos de própolis verde e marrom, após 5 dias do tratamento. Letras distintas na mesma coluna indicam diferença significativa pelo teste de Scott-Knott, $5 \%$ de significância. Para análise os dados foram transformados $(\sqrt{x}+5)$.

\begin{tabular}{|c|c|c|c|c|c|c|}
\hline \multirow[b]{2}{*}{ Tratamentos } & \multicolumn{2}{|c|}{ Antracnose } & \multicolumn{2}{|c|}{ Mofo cinzento } & \multicolumn{2}{|c|}{ Podridão de Rhizopus } \\
\hline & $\begin{array}{c}\text { Incidência } \\
(\%)\end{array}$ & Severidade $^{1}$ & $\begin{array}{c}\text { Incidência } \\
(\%)\end{array}$ & Severidade & $\begin{array}{c}\text { Incidência } \\
(\%)\end{array}$ & Severidade \\
\hline Água+Álcool 2\% & $100,00 \mathrm{a}$ & $3,50 \mathrm{a}$ & $80,00 \mathrm{a}$ & $1,17 \mathrm{a}$ & $0,00 \mathrm{~b}$ & $0,00 \mathrm{~b}$ \\
\hline Própolis verde $0,5 \%$ & $93,33 \mathrm{a}$ & $2,63 \mathrm{~b}$ & $69,99 \mathrm{a}$ & $0,90 \mathrm{a}$ & 39,99 a & $0,70 \mathrm{a}$ \\
\hline Própolis verde $2,5 \%$ & $100,00 \mathrm{a}$ & $3,49 \mathrm{a}$ & $70,00 \mathrm{a}$ & $0,97 \mathrm{a}$ & $3,33 \mathrm{~b}$ & $0,03 \mathrm{~b}$ \\
\hline Própolis marrom $0,5 \%$ & $93,33 \mathrm{a}$ & $3,13 \mathrm{a}$ & $70,00 \mathrm{a}$ & $0,97 \mathrm{a}$ & $23,33 \mathrm{a}$ & $0,70 \mathrm{a}$ \\
\hline Própolis marrom 2,5\% & $100,00 \mathrm{a}$ & $3,59 \mathrm{a}$ & $70,00 \mathrm{a}$ & $0,93 \mathrm{a}$ & $3,33 \mathrm{~b}$ & $0,03 \mathrm{~b}$ \\
\hline $\mathrm{CV}(\%)$ & 2,86 & 12,20 & 11,95 & 3,19 & 17,80 & 3,87 \\
\hline
\end{tabular}

Valores estimados por escala de notas, onde $0=$ sem infecção; $1=25 \%$ do fruto infectado; $3=50 \%$ do fruto infectado; $4=100 \%$ infecção.

Os extratos brutos aquosos de plantas espontâneas a $10 \%$, não tiveram efeito sobre as doenças pós-colheita no experimento in vivo, não havendo diferença significativa na incidência e severidade de antracnose, mofo cinzento e podridão de Rhizopus em relação à testemunha (Tabela 2). Uma explicação para este fato, provavelmente, seja a variação da composição em quantidade de princípio ativo das plantas, os quais são produzidos pelo metabolismo secundário e são altamente influenciados pelo ambiente e a forma de extração desses compostos.

Segundo Teste; Trentini (1997) a concentração de princípios ativos nas plantas medicinais não se apresenta uniforme durante o ciclo de vida da planta, variando com o habitat, a colheita e a preparação, sendo fundamental a observação de fatores como procedência, identificação botânica, colheita (estágio de desenvolvimento da planta, época e horário de coleta), tratamentos fitossanitários e qualidade (MING, 1994). Rozwalka et al. (2008) ainda ressalta que, além dos fatores acima citados, a forma de aproveitamento do material vegetal (seco ou fresco), os métodos de extração, bem como as concentrações utilizadas, resultarão em maior eficiência e credibilidade dos resultados.

Tabela 2. Incidência e severidade de doenças pós-colheita em morangos tratados com extratos aquosos de plantas espontâneas, após 5 dias do tratamento. Para a análise os dados foram transformados $(\sqrt{x}+5)$.

\begin{tabular}{ccccccc}
\hline \multirow{2}{*}{ Tratamentos } & \multicolumn{2}{c}{ Antracnose } & \multicolumn{2}{c}{ Mofo cinzento } & \multicolumn{2}{c}{ Podridão de Rhizopus } \\
\cline { 2 - 6 } & Incidência (\%) & Severidade $^{1}$ & Incidência (\%) $^{\text {Severidade }}$ & Incidência (\%) & Severidade \\
\hline Água & 96,67 & 3,60 & 80,00 & 1,33 & 0,00 & 0,00 \\
Assa-peixe 10\% & 100,00 & 3,53 & 90,00 & 1,27 & 6,00 & 0,23 \\
Rubim 10\% & 100,00 & 3,43 & 93,33 & 1,53 & 3,33 & 0,03 \\
Língua-de-vaca 10\% & 100,00 & 3,80 & 83,33 & 1,36 & 5,00 & 0,33 \\
Tansagem 10\% & 100,00 & 3,43 & 66,66 & 0,93 & 3,33 & 0,03 \\
\hline CV (\%) & 3,36 & 7,19 & 5,90 & 2,44 & 12,30 & 5,29 \\
\hline
\end{tabular}

${ }^{1}$ Valores estimados por escala de notas, onde $0=$ sem infecção; $1=25 \%$ do fruto infectado; $3=50 \%$ do fruto infectado; $4=100 \%$ infecção. 
Os dados obtidos no presente trabalho assemelham-se aos citados por Almeida et al. (2009) que estudando sobre o controle de patógenos pós-colheita em frutos de morangos, submetidos aos extratos de arnica e nim à $20 \%$, observaram que não houve diferença significativa dos extratos em relação à testemunha.

Dotto et al. (2014) não verificaram efeito de extratos vegetais de folhas de pitangueira (Eugenia uniflora), flores de calêndula (Calendula officinalis) e capítulo floral de cravo da índia (Syzygium aromaticum) e calda bordalesa, aplicados na pré-colheita do morangueiro sobre a incidência de podridões do mofo cinzento e esporulação de fungos (Botrytis cinerea).

\section{CONCLUSÕES}

Os extratos etanólicos de própolis verde e marrom a $2,5 \%$ apresentaram capacidade antifúngica in vitro a $B$. cinerea nos três tempos de avaliação.

O extrato aquoso da planta espontânea rubim apresentou ter ação fungitóxica sobre $B$. cinérea, enquanto que extratos aquosos língua-de-vaca, assa-peixe e tansagem estimularam o crescimento do patógeno.

Os frutos de morangos tratados com extrato etanólico de própolis verde a $0,5 \%$ apresentaram menor severidade da antracnose.

Os tratamentos com própolis verde e marrom a 2,5\% reduziram a incidência e severidade da podridão de Rhizopus, apresentado ser potenciais produtos alternativos no controle de patógenos pós-colheita.

Os extratos etanólicos de própolis não tiveram efeito sobre a incidência e severidade do mofo cinzento nos frutos de morangueiro, bem como os extratos brutos aquosos de plantas espontâneas a $10 \%$, não tiveram efeito sobre as doenças pós-colheita no experimento in vivo.

\section{REFERÊNCIAS}

ALBANO, E.M.S.; ZAINA, T.C.; ZANIN, D.G.; GONÇALVES, R.A. Avaliação da ação do extrato da borra da própolis no controle de sanidade de sementes de feijão. Fitopatologia Brasileira, v. 32, p.147, 2007. (Suplemento).

ALMEIDA, T. F; CAMARGO, M; PANIZZI, R. C. Efeito de extratos de plantas medicinais no controle de Colletotrichum acutatum, agente causal da flor preta do morangueiro. Summa Phytopathologica, v.35, n.3, p.196-201, 2009.

BARBOSA, M.S.; VIEIRA, G.H.C.; TEIXEIRA, A.V. Atividade biológica in vitro de própolis e óleos essenciais sobre o fungo Colletotrichum musae isolado de bananeira (Musa spp.). Revista Brasileira de Plantas Medicinais. v.17, n.2, 2015.

BENATO, E.A.; SIGRIS, J.M.M.; HANASHIRO, M.M.; MAGALHÃES, M. J.M; BINOTTI, C.S. Avaliação de fungicidas e produtos alternativos no controle da podridão pós-colheita em maracujá-amarelo. Summa Phytopathologica, v.28, p.299-304. 2002.

BIANCHINI, L.; BEDENDO, I.P. Efeito antibiótico do própolis sobre bactérias fitopatogênicas. Scientia Agrícola, v.55, p.149-152, 1998.
BRAGA, D.O. Qualidade pós-colheita de morangos orgânicos tratados com óleos essenciais na pré-colheita. Dissertação (mestrado). Universidade Federal de Lavras, 2012. 74p.

BURG, I.C.; MAYER, P.H. Alternativas ecológicas para prevenção e controle de pragas e doenças. 30 ed. Francisco Beltrão: Grafit Gráfica e Editora Ltda. 2006, 153p.

CANTILLANO, R.F.F.; SILVA, M.M. Manuseio póscolheita de morangos. Embrapa Clima Temperado. Documentos, 318. Pelotas: Embrapa Clima Temperado; 2010. p.36.

CARVALHO, V. L.; CUNHA, R. L.; CHALFUN, N.N.J.; MOURA, P.H.A. Alternativas de controle pós-colheita da podridão-parda e da podridão-mole em frutos de pessegueiro. Revista Brasileira Fruticultura, v.31, n. 1, p.078-083, 2009.

CSC - CALIFORNIA STRAWBERRY COMMISSION; THE CALIFORNIA MINOR CROPS COUNCIL. A pest management strategic plant for strawberry in California. 2013. Disponível em:< http:// www.ipmcenters.org $\backslash p m s p \backslash p d f \backslash C A S T R A W B E R R Y . P D F>$ Acesso em: 02 fev.2016.

DEMARTELAERE， A.C.F.; GUIMARÃES， G.H.C.1; SILVA, J.A.1; LUNA, R.G.1; NASCIMENTO, C.L. Extratos vegetais no controle da antracnose e na conservação da qualidade em frutos de mamoeiro. Revista Brasileira de Plantas Medicinais, v.17, n.4, p.1041-1048, 2015.

DOTTO, M.C.; POMBO, M.A.; MARTINEZ, G.A.; CIVELLO, P.M. Heat treatments and expansin gene expression in strawberry fruit. Scientia Horticulturae, v.130, n.4, p.775-780, 2011.

EMATER-DF. Empresa de Assistência Técnica e Extensão Rural do Distrito Federal. Produção Agropecuária 2011. Disponível em: http://www.emater.df.gov.br/ Acesso: 02 de maio 2014.

FERREIRA, D.F. SISVAR: Sistema de análise de variância para dados balanceados, versão 5.0. Lavras: DEX/UFLA, 2007. CD-ROM. Software.

FRANCO, D.A.; BETTIOL, W. Controle de Penicillium digitatum em pós-colheita de citros com produtos alternativos. Fitopatologia Brasileira, v.25, p.602-606, 2000.

GEBEL, M.P.; MAGURNO, F. Assessment of the antifungal potential of the essential oil from Thymus vulgaris against Botrytis cinerea causative agent of post harvest grey mold on strawberry fruits. Columella - Journal of Agricultural and Environmental Sciences, v.1, n.2, p.17-23, 2014.

JARDIM, A.N.O.; CALDAS, E.D. Brazilian monitoring programs for pesticide residues in food - results from 2001 to 2010. Food control, v.25, p.607-616, 2012.

LORENZETTI, E.R. Controle de doenças do morangueiro com óleos essenciais e Trichoderma spp. Tese de doutorado. Universidade Federal de Lavras: UFLA, 2012. 106p.

LORENZI, H.; MATOS, F.J.A. Plantas medicinais no Brasil: nativas e exóticas. Nova Odessa: Instituto Plantarum, 2002, $544 \mathrm{p}$. 
MALGARIM, M.B.; CANTILLANO, R.F.F.; COUTINHO, E.F. Sistemas e condições colheita e armazenamento na qualidade de morangos cv. Camarosa. Revista Brasileira de Fruticultura. v.28, n.2, 2006.

MARINI, D.; MENSCH, R.; FREIBERGER, M.B.; DARTORA, J.; FRANZENER, G.; GARCIA, R.C.; STANGARLIN J.R. Efeito Antifúngico de extratos alcoólicos de própolis sobre patógenos da videira. Arquivos do Instituto Biológicos, São Paulo, v.79, n.2, p.305-308, 2012.

MARQUENIE, D.; LAMMERTYN, J.; GEERAERD, A. H.; Inactivation of conidia of Botrytis cinerea and Monilinia fructigena using UV-C and heat treatment. International Journal of Food Microbiology, v.74, p. 7 -35, 2002.

MEDEIROS CAB; STRASSBURGER AS; GOMES CB WOLFF LF. 2008. Controle alternativo de requeima (Phytophthora infestans) em batata cultivada em sistema de base ecológica. Horticultura Brasileira 26: S4821-S4825.

MING, L.C. Estudo e pesquisa de plantas medicinais na agronomia. Horticultura Brasileira, v.12, n.1, p.2-9, 1994.

MORAES, W. B; JESUS JUNIOR, W. C; BELAN, L. L; PEIXOTO, L. A; PEREIRA, A. J. Aplicação foliar de fungicidas e produtos alternativos reduz a severidade do oídio no tomateiro. Nucleus, v. 8, n. 2, 2011.

MOREIRA, L.M.; MAY-DE MIO, L.L.; ALDEBENITOSANHUEZA, R.M.; LIMA, M.L.R.Z; POSSAMAI, J.C. Controle em pós-colheita de Monilia fructiola em pêssegos. Fitopatologia Brasileira, v.27, p.395-398, 2002.

MOURA, G.S.; SCHWAN-ESTRADA，K.R.F.; ALVES, A.P.F.; FRANZENER, G.; STANGARLIN, J.R. Controle da antracnose em maracujá-amarelo por derivados de capimlimão (Cymbopogon citratus). Arquivos do Instituto Biológico, v.79, n.3, p.371-379, 2012.

OZCAN, M. Antifungal properties of propolis. Grasas y Aceites. v.50, n.5, p.395-398, 1999.

PANSERA, M. R.; PAULETTI, M.; GONZALEZ, A.; SARTORI, V.C.; RIBEIRO, R.T.S. Utilização de tinturas vegetais e óleo essencial no controle do mofo-branco em alface. Revista Brasileira de Agroecologia. v.10, n.2, p.87-91, 2015.

PEREIRA, C. S.; MAIA, L. F. P.; PAULA, F. S. Aplicação de extrato etanólico de própolis no crescimento e produtividade do feijoeiro comum. Revista Ceres, v.61, n.1, 2014.

PIERMANN, L.; SILVA, I.T.; OLIVEIRA, J.R.; FUJINAWA, M.F.; LIMA, H.E.; PONTES, N.C. Efeito de extratos vegetais e própolis sobre o crescimento in vitro de fitobactérias. Fitopatologia Brasileira, v.32, p.156, 2007. Suplemento

REIS, A., COSTA. H. Principais doenças do morangueiro no Brasil e seu controle. Circular Técnica. MAPA, Brasília, 2011.

ROZWALKA, L.C.; LIMA, M.L.R.Z.C.; MIO, L.L.M.; NAKASHIMA.T. Extratos, decoctos e óleos essenciais de plantas medicinais e aromáticas na inibição de Glomerella cingulata e Colletotrichum gloeosporioides de frutos de goiaba. Ciência Rural, v. 38, n. 2, p. 301-307, 2008.

SÁ, C. R. L.; SILVA, E. O.; TERAO, D. OSTER, A.H. Eficiência de métodos alternativos utilizando atmosfera modificada passiva, no controle da podridão de melão Cantaloupe. Revista Caatinga, v.21, n.4, p.35-42. 2008.

SAUTTER, C.K.; BRACKMANN, A.; ANESE, R.O.; WEBER, A.; RIZZATTI, M.R.; PAVANELLO, E.P. Controle da podridão-parda e características físico-químicas de pêssegos 'Magnum' submetidos a tratamentos pós-colheita com elicitores abióticos. Revista Ceres, Viçosa, v. 58, n.2, p. 172-177, 2011.

SCHWARZ, L.L; MONTERO, C.R.S.; SANTOS, L.C. Efeito de tratamentos alternativos nas propriedades qualitativas de pêssego cv. Maciel. Resumo apresentado no XX Congresso Brasileiro de Fruticultura. Vitória/ ES, 2008.

SILVA, A. F. Própolis: Caracterização físico-química, atividade antimicrobiana e antioxidante. 2009. 145p. Tese (Doutorado). Universidade Federal de Viçosa, MG.

SIMARELLI, M. Fruto na mesa: tempo de morango. Revista Frutas e Derivados. IBRAF, ano 1, ed. 02, junho de 2006.

TANAKA, M. A. S.; BETTI, J. A.; KIMATI, H. Doenças do morangueiro. In: KIMATI, H.; AMORIM, L.; REZENDE, J. A. M.; BERGAMIN FILHO, A.; CAMARGO, L. E. A. (Ed.). Manual de fitopatologia: doenças das plantas cultivadas. 4. ed. São Paulo: Agronômica Ceres, 2005. v. 2, p. 489-499.

TESKE, M.; TRENTINI, A.M.M. Herbarium compêndio de fitoterapia. 3.ed. Curitiba: Herbarium Laboratório Botânico, 1997. 317p.

TOURNAS, V. H.; KATSOUDAS, E. Mould and yeast flora in fresh berries, grapes and citrus fruits. International Journal of Food Microbiology, Amsterdam, v. 105, n. 1, p. 11-17, 2005.

VENENCIO, G. Avaliação da degradação de pelargonidina durante a secagem de morangos. (Trabalho de conclusão de graduação). Universidade Federal do Rio Grande do Sul. Porto Alegre, 2010.

VENZON M. ;ROSADO, M.C.; PINTO, C.M.F.; DUARTE, V.S., EUZÉBIO, D.E., PALLINI, A. Potencial de defensivos alternativos para o controle do ácaro branco em pimenta "Malagueta". Horticultura Brasileira v. 24 p. 224-227, 2006.

VU, K. D.; HOLLINGSWORTH, R. G.; SALMIERI, S.; LACROIX, M. Development of edible bioactive coating based on modified chitosan for increasing the shelf life of strawberries. Food Research International, Barking, v. 44, n. 1, p. 198-203, 2011.

ZAMBOLIM, L.; COSTA. H. Manejo integrado de doenças do morangueiro. In: CARVALHO, S. P. (Coord.). Boletim do morango: cultivo convencional, segurança alimentar, cultivo orgânico. Belo Horizonte: CEASA Minas, 2005. p. 55-96. 